\title{
Non-invasive monitoring of blood gas-induced changes of myocardial oxygenation using oxygen-sensitive CMR
}

\author{
Dominik P Guensch*, Kady Fischer, Jacqueline Flewitt, Janelle Yu, Ryan Lukic, Julian A Friedrich, \\ Matthias $G$ Friedrich
}

From 15th Annual SCMR Scientific Sessions

Orlando, FL, USA. 2-5 February 2012

\section{Summary}

BOLD-CMR was used to assess changes in myocardial oxygenation after volunteers performed controlled hyperventilation or breath holding. Signal intensity after hyperventilation decreased whereas an increase occurred after a breath hold demonstrating that controlled breathing techniques could alter myocardial oxygenation and be identified by BOLD-CMR in healthy volunteers.

\section{Background}

Systemic changes of blood gases $\left(\mathrm{CO}_{2}, \mathrm{O}_{2}\right)$ affect haemoglobin $(\mathrm{Hb})$ saturation. Blood Oxygen Level-Dependent (BOLD-) CMR can be used to monitor changes of myocardial oxygenation. We hypothesized that oxygensensitive CMR detects changes in myocardial tissue oxygenation induced by hyperventilation and apnea.

\section{Methods}

A group of 7 healthy volunteers were instructed to hyperventilate for 1 and 2 minutes followed by a long free breath hold. A second group of 5 aquatic athletes performed a 60 s breath hold and a free maximal breath hold. BOLD-sensitive SSFP cines were acquired during breath holds as well as before and after hyperventilation. Changes in signal intensity over the procedures were expressed as \% change of the baseline. Capillary blood gases were measured prior to and after the procedures.

\section{Results}

Voluntary breath holds of athletes were significantly longer $(105 \pm 38 \mathrm{~s})$ than those of other volunteers $(38$ $\pm 12 \mathrm{~s})$. Breath holds lead to a significant increase in signal intensity (" $\mathrm{p}<0.001)$, correlated with the length of breath hold ( $\mathrm{R}=0.566$, " $\mathrm{p}=0.018)$. Capillary $\mathrm{pCO}_{2}$ did not change during breath holds, while $\mathrm{pO}_{2}$ increased during shorter breath holds of $38 \mathrm{~s}\left(+8.8 \mathrm{mmHg},{ }^{*} \mathrm{p}=0.03\right)$ and decreased in long breath holds of $105 \mathrm{~s}(-14.5 \mathrm{mmHg}$, " $\mathrm{p}=0.03)$. On the other hand, hyperventilation resulted in a significant decrease of myocardial signal intensity, associated with a decrease of capillary $\mathrm{pCO}_{2}$ of 5.9 $\mathrm{mmHg}$ during $1 \mathrm{~min}$ of hyperventilation ("p<0.001) and $8.7 \mathrm{mmHg}$ during a $2 \mathrm{~min}$ hyperventilation period $($ " $\mathrm{p}<0.001)$. Capillary $\mathrm{pO}_{2}$ was not altered by hyperventilation.

\section{Conclusions}

Our results demonstrate that BOLD-CMR can identify changes in myocardial oxygenation induced by controlled breathing maneuvers.

\section{Funding}

Husky Energy Program for the Early Detection of Cardiovascular Disease

Published: 1 February 2012

doi:10.1186/1532-429X-14-S1-P285

Cite this article as: Guensch et al:: Non-invasive monitoring of blood gas-induced changes of myocardial oxygenation using oxygen-sensitive CMR. Journal of Cardiovascular Magnetic Resonance 2012 14(Suppl 1):P285.

Kady Fischer, Stephenson Cardiovascular MR Centre, Calgary, AB, Canada 


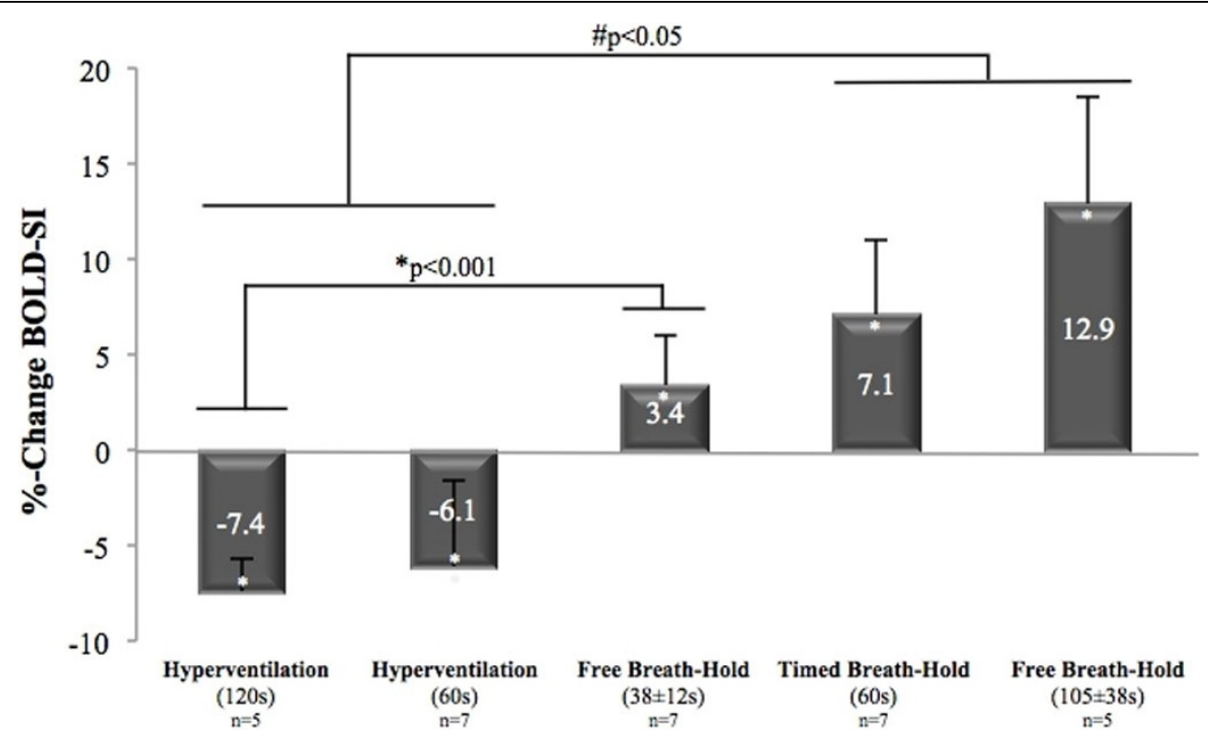

Figure 1 The \%-change in SI was significant after hyperventilation or a breath hold $\left({ }^{*} p<0.001\right)$ as the \%-change in SI was significant between groups undergoing hyperventilation or a breath hold (\#p<0.05). 